\title{
Usefulness of the Signal-Averaged Electrocardiogram for Evaluating the Block Site of Right Bundle Branch Block Following Surgical Correction of a Congenital Heart Disease
}

\author{
Hiroshi Akrta, M.D., Suguru Matsuoka, M.D., Yoshiyuki Taguahi, M.D., \\ Masahiro Kubo, M.D., and Yasuhiro Kuroda, M.D.
}

\begin{abstract}
SUMMARY
It is important to distinguish proximal right bundle branch block (RBBB) from distal RBBB because patients with both proximal RBBB and left bundle branch block may progress to a late atrioventricular conduction disturbance. Signal-averaged electrocardiograms (SAECGs) were investigated in 35 patients with $\mathrm{RBBB}$ following surgical correction of tetralogy of Fallot or ventricular septal defect in order to determine the block site of RBBB noninvasively using a SAECG. The site of RBBB was first identified by a body surface map; 12 patients had proximal RBBB (group 1), and 23 had distal RBBB (group 2). The control groups consisted of 8 patients with RBBB without congenital heart disease (group 3) and 20 normal subjects (group 4). The mean of the filtered QRS duration in the group 1 patients was significantly longer than in the other 3 groups $(p<0.01)$. The number of fragmented signals in group 1 was significantly greater than that in the other 3 groups $(p<0.01)$. A filtered $Q R S$ pattern was divided into 4 different types (whole, early, late, and normal) according to the successive fragmented signals; the "whole" type was the most common in group $1(83 \%)$. SAECG is successful in identifying those patients with proximal RBBB according to the following indices: a filtered QRS duration equal to or longer than $160 \mathrm{msec}$, a fragmented signal number greater than 10 and a "whole" type filtered QRS pattern. In conclusion, SAEGG is a useful tool for distinguishing proximal RBBB from distal RBBB. (Jpn Heart J 34: 183-192, 1993.)
\end{abstract}

\section{Key Words:}

Signal-averaged electrocardiogram Congenital heart disease Right bundle branch block Block site

$7 \mathrm{HE}$ most common cause of right bundle branch block (RBBB) in children is a result of the surgical correction of congenital heart disease, most commonly ventricular septal defect and tetralogy of Fallot. A surgical incision

From the Department of Pediatrics, University of Tokushima, School of Medicine, Tokushima, Japan. Mailing address: Hiroshi Akita, M.D., Department of Pediatrics, National Kagawa Children's Hospital, Zentsuzi-cho 2603, Zentsuzi City, Kagawa, Japan 765.

Received for publication May 20, 1992.

Accepted September 7, 1992. 
can result in an injury to the proximal right bundle branch or the Purkinje fibers, or cause local fibrosis or ischemia. These injuries may lead to ventricular conduction disturbances, ventricular arrhythmias or heart failure. ${ }^{1-4)}$ It is important to evaluate the site of RBBB in postoperative patients with congenital heart disease, since some patients with proximal RBBB can develop late atrioventricular conduction disturbances. ${ }^{4}$ )

Although the site of RBBB is best determined by epicardial or endocardial electrophysiologic recordings, ${ }^{11,2,5)}$ these methods are invasive. A body surface map is also useful for demonstrating the site of RBBB by evaluating the position where the block appeared and the time of the breakthrough minimum. ${ }^{6,7)}$ However, this method is problematic in children.

It has been established that the signal-averaged electrocardiogram (SAECG) will record late potentials, ${ }^{8)-15)}$ but there has been no published study which has reported its usefulness in determining the site of RBBB. In this study we compare the use of SAECGs with body surface maps in order to determine noninvasively the block site in patients with RBBB following the surgical correction of tetralogy of Fallot or ventricular septal defect.

\section{Materuais and Methods}

Thirty-five patients (19 males and 16 females) with RBBB following the surgical correction of tetralogy of Fallot (20 patients) or ventricular septal defect (15 patients) were studied. The mean age $( \pm \mathrm{SD}$ ) of the patients was 10.4 \pm 5.7 years (range, 4 to 27 years) and the mean time elapsed from operation to the present study was 6.1 years (range, 1 to 18 years). Twenty-five patients had complete RBBB, and 10 had incomplete RBBB. The patients with late potentials ${ }^{15)}$ were excluded from this study because late potentials affect the parameters of SAECG.

A body surface map was generated in an attempt to determine the site of RBBB by analyzing its position and the time of the breakthrough. The RBBB was considered to be due to a proximal block when the breakthrough appeared to the left of the normal position and was delayed by more than $30 \mathrm{msec}$. When the breakthrough appeared at the normal position and within the normal time, the site of RBBB was considered to be distal. The 35 patients were divided into 2 groups: those with proximal RBBB (group 1) and those with distal RBBB (group 2). The control groups consisted of 8 patients with RBBB and no congenital heart disease (group 3; 4 with complete RBBB, 4 with incomplete RBBB), and 20 normal subjects without bundle branch block (group 4).

The SAEGGs were recorded using a VCM-3000 (Fukuda Co.). The signals from a total of 256 beats were averaged by the vector-magnitude method de- 

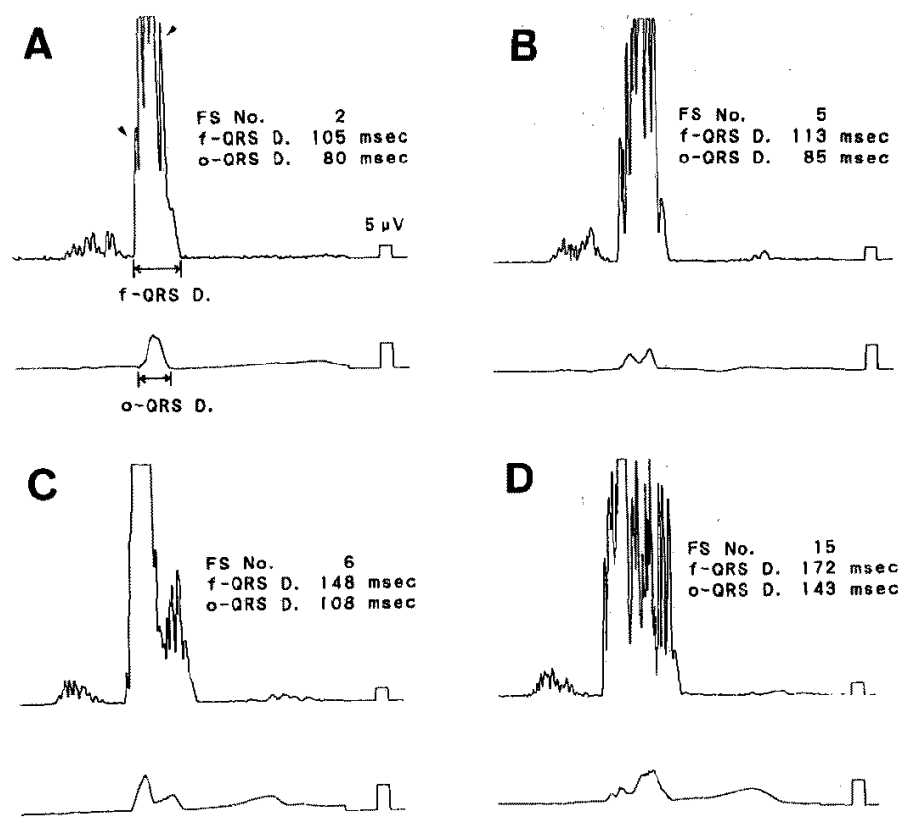

Fig. 1. Typical signal-averaged electrocardiogram (SAECG) divided into four categories. A: Normal type. The SAECG from a normal subject. The arrows indicate fragmented signals. B: Early type. The SAECG from a patient with distal right bundle branch block (RBBB). C: Late type. The SAECG from a patient with distal RBBB and no congenital heart disease. D: Whole type. The SAECG from a patient with proximal RBBB. Upper figure represents filtered QRS, lower figure depicts nonfiltered QRS (original QRS). Filtered QRS duration, number of fragmented signals in the filtered $Q R S$, and original QRS duration are described in each figure. $f-Q R S D .=$ filtered QRS duration; FS No. = number of fragmented signals; $o-Q R S D .=$ oniginal $Q R S$ duration.

scribed by Simson. ${ }^{8)}$ Signals from the bipolar X, Y, and Z leads were amplified (amplification factor of $1000 \mathrm{X}$ ) with a $40-$ to $300-\mathrm{Hz}$ bandwidth. The magnitude of the vector was calculated for each point of the averagcd wave with:

$$
\mathrm{V}=\sqrt{\mathrm{X}^{2}+\mathrm{Y}^{2}+\mathrm{Z}^{2}}
$$

The filtered QRS ( $\mathrm{f}-\mathrm{QRS}$ ) duration, and the number of fragmented signals (FS) in the $\mathrm{f}-\mathrm{QRS}$ were measured (Fig. 1A). FS were defined as low amplitude signals of less than $100 \mu \mathrm{V}$, because the maximum amplitude of the SAECG in our study was $100 \mu \mathrm{V}$. Those FS under $3 \mu \mathrm{V}$ were not counted so as to exclude noise. A poly-FS was considered to be a series of FS greater than 3 , because most of the normal subjects had less than 3 successive FS in the initial QRS and in the terminal QRS. The $\mathrm{f}-\mathrm{QRS}$ pattern was characterized into one of 4 types according to the position of the poly-FS in the $\mathrm{f}-\mathrm{QRS}$; whole, early, late, and normal (without any poly-FS) (Fig. 1). The nonfiltered QRS (original QRS: o- 
QRS) duration was also measured.

The data were analyzed using a one-way analysis of variance (ANOVA) and Student's t-test, and differences were considered significant at a level of $\mathrm{p}<0.05$.

\section{Results}

\section{The site of RBBB}

Representative maps are presented in Fig. 2. The first (Fig. 2A) is a body surface map from a 14-year-old boy who presented with RBBB after the surgical correction of tetralogy of Fallot. The breakthrough (shown by the arrow) appeared in the normal area and without a significant delay. Accordingly, the block site was considered to be distal. On the other hand, the second body surface map (Fig. 2B) is from a 15-year-old boy who presented with RBBB after the surgical correction of tetralogy of Fallot. The breakthrough appeared to the left of the normal position and was delayed. This patient was considered to have proximal RBBB.

Using this map technique, we categorized 12 patients as having proximal

A

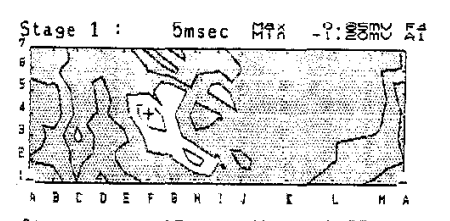

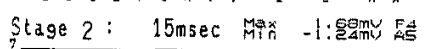

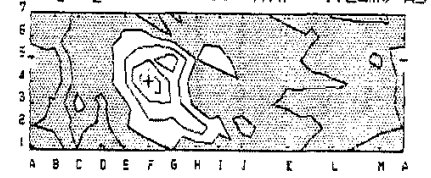

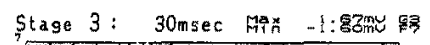

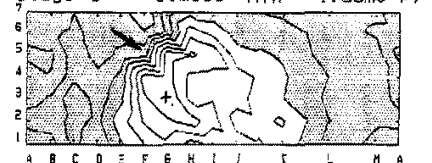

Stage 4: 50msec Mix -

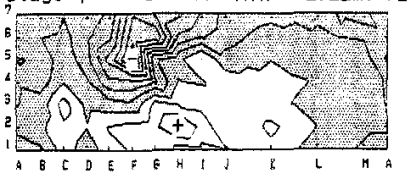

B

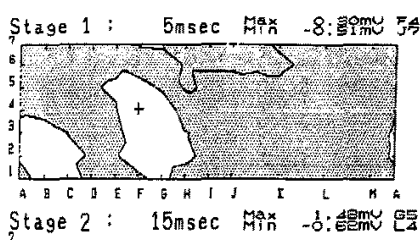

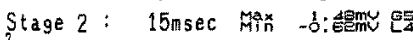

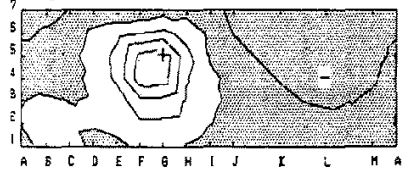

Stage 3: 35nsec Min -1: agmu Je

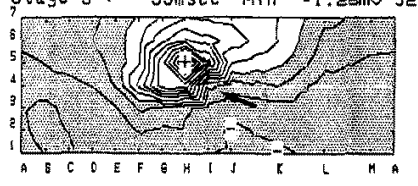

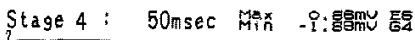

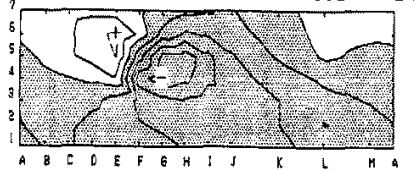

Fig. 2. Typical body surface map. A: The body surface map from a patient with distal right bundle branch block (RBBB) (the same patient as in Fig. 1B). B: The body surface map from a patient with proximal RBBB (the same patient as in Fig. 1D). The arrow indicates the position of the breakthrough. 
RBBB (group 1), and 23 as having distal RBBB (group 2). All patients in group 3 were considered to have distal RBBB.

\section{SAECG}

Typical SAECGs from a patient in each group are presented (Fig. 1). The SAECG from a healthy 13-year-old girl is presented in Fig. 1A. The $\mathrm{f}-\mathrm{QRS}$ pattern was a "normal" type. The SAECG of the patient with distal RBBB presented in Fig. 1B had a $\mathrm{f}-\mathrm{QRS}$ duration of $113 \mathrm{msec}$ and an o-QRS duration of $85 \mathrm{msec}$. The $\mathrm{f}-\mathrm{QRS}$ pattern was considered to be an "early" type, and $5 \mathrm{FS}$ were observed. The SAECG obtained from an 8-year-old boy with distal RBBB without congenital heart disease is shown in Fig. $1 \mathrm{C}$. The $\mathrm{f}-\mathrm{QRS}$ pattern was a "late" type. The SAECG of the patient presented in Fig. ID had a $\mathrm{f}-\mathrm{QRS}$ duration of $172 \mathrm{msec}$ and an o-QRS duration of $143 \mathrm{msec}$. Many FS (15) were observed throughout the $f-Q R S$, so that the $f-Q R S$ pattern was classified as a "whole" type.

The $f-Q R S$ duration in the group 1 patients was significantly longer than that in the other 3 groups (Fig. 3, p<0.01). Most patients in group 1 had a $\mathrm{f}-$ QRS duration equal to or longer than $160 \mathrm{msec}$, while most patients in the other groups had a $\mathrm{f}-\mathrm{QRS}$ duration of less than $160 \mathrm{msec}$.

The group 1 patients had the highest mean number of FS among the 4 groups. A significant difference was noted in the number of FS between the
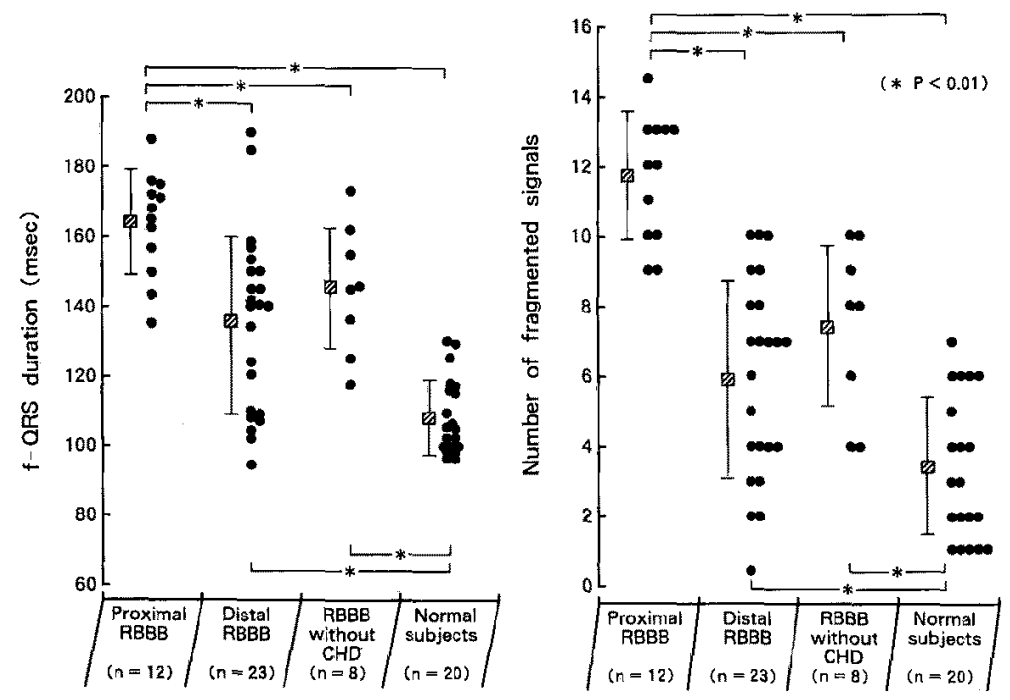

Fig. 3. The filtered $Q R S$ duration and the number of fragmented signals in patients with right bundle branch block and in normal subjects. Data are expressed as mean $\pm S D$. $C H D=$ congenital heart disease; $f-Q R S=$ filtered $Q R S ; R B B B=$ right bundle branch block. 


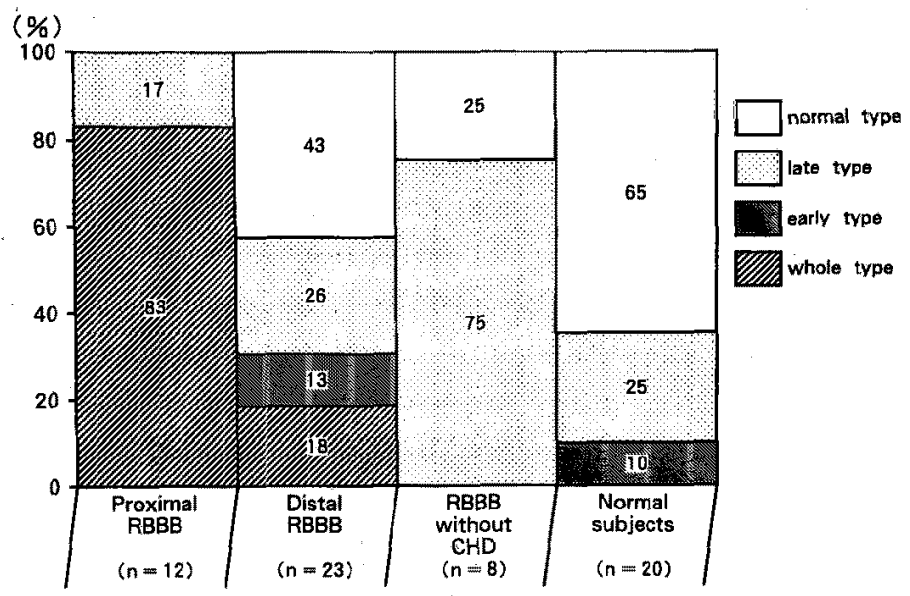

Fig. 4. The proportion of the four filtered QRS patterns in patients with right bundle branch block and in normal subjects. Abbreviations are the same as those in Fig. 3.

group 1 patients and those in the other 3 groups (Fig. 3, p<0.01), and also between those in group 4 and those in groups 2 and $3(\mathrm{p}<0.01)$. Most patients in group 1 had greater than $10 \mathrm{FS}$, while all subjects in the other groups had 10 or less.

The $f-Q R S$ patterns in the 4 groups are summarized in Fig. 4. The "whole" type was the most common in the group 1 patients (83\%) but was rare in the other groups. Most patients in groups 2, 3, and 4 demonstrated an "early", "late", or "normal" type of pattern.

\section{The criteria for proximal RBBB}

These results suggested that the criteria for proximal RBBB by the SAECG can be considered to be: an $\mathrm{f}$ - QRS duration equal to or more than $160 \mathrm{msec}$,

Table I. Analysis of Criteria for Proximal Right Bundle Branch Block

\begin{tabular}{lcccc}
\hline & Sensitivity & Specificity & $\begin{array}{c}\text { Positive } \\
\text { predictive } \\
\text { value }\end{array}$ & $\begin{array}{c}\text { Negative } \\
\text { predictive } \\
\text { value }\end{array}$ \\
\hline (1) f-QRS duration & $67 \%$ & $91 \%$ & $80 \%$ & $84 \%$ \\
(2) number of FS & $67 \%$ & $100 \%$ & $100 \%$ & $85 \%$ \\
(3) f-QRS pattern & $83 \%$ & $83 \%$ & $71 \%$ & $90 \%$ \\
(1) and (2) and (3) & $42 \%$ & $100 \%$ & $100 \%$ & $77 \%$ \\
(1) or (2) or (3) & $100 \%$ & $74 \%$ & $67 \%$ & $100 \%$ \\
\hline
\end{tabular}

The criteria are as follows: (1) f-QRS duration equal to or longer than $160 \mathrm{msec}$, (2) more than $10 \mathrm{FS}$, (3) the "whole" type $\mathrm{f}-\mathrm{QRS}$ pattern. $\mathrm{f}-\mathrm{QRS}=$ filtered QRS; FS = fragmented signal. 
more than $10 \mathrm{FS}$, and a "whole" type $\mathrm{f}-\mathrm{QRS}$ pattern. The diagnostic value of the SAECG in interpreting proximal RBBB is shown in Table I. Using a single criterion, the $f-Q R S$ pattern was the most sensitive of the 3 parameters, while the number of FS had the greatest specificity. Moreover, the sensitivity and the negative predictive value were $100 \%$ when at least one criterion out of three was present.

\section{Discussion}

SAECG has been used to detect from the body surface the low amplitude and the high-frequency potentials at the end of the QRS complex. These low amplitude, late potentials are commonly observed in patients with ischemic heart disease and dilated cardiomyopathy, and are also associated with critical arrhythmias such as ventricular tachycardia or fibrillation. ${ }^{8)-14)}$ However, most previous studies of late potentials have excluded patients with a bundle branch block because ventricular conduction disturbances affect the $\mathrm{f}-\mathrm{QRS}$ duration, the amplitude of $\mathrm{f}-\mathrm{QRS}$, and the duration of the terminal low-amplitude signal. ${ }^{16)}$ In recent years, there have been several reports on the SAECG findings in patients with left bundle branch block and in postoperative patients with bundle branch block. It was reported that the SAEGG could be used in such patients if the criteria for the interpretation of the SAECG were altered. ${ }^{15)-19)}$ However, there have been few clinical applications of the SAECG except for the detection of late potentials. This study attempted to take advantage of the SAECG for determining the block site in patients who present with RBBB after the surgical correction of tetralogy of Fallot or ventricular septal defect.

The FS in this study were defined as small, high-frequency electrical signals between 3 and $100 \mu \mathrm{V}$, which responded to the action potentials from the Purkinje fibers. In normal subjects the FS was also observed to be equal to or less than 7 with a band-path filter of $40-300 \mathrm{~Hz}$. Buckingham et al, ${ }^{16)}$ also demonstrated the electrical fragmentation on SAECG similar to FS from patients with left bundle branch block. However, further analysis was not done.

The site of RBBB was interpreted noninvasively by measuring the $f-Q R S$ duration, the number of FS, and the $f-Q R S$ pattern of SAECG. The findings useful in detecting proximal RBBB were: a $f-Q R S$ duration equal to or longer than $160 \mathrm{msec}$, more than $10 \mathrm{FS}$, and the "whole" type $\mathrm{f}-\mathrm{QRS}$ pattern. The patients with proximal RBBB had a significantly greater number of FS and a longer $f-Q R S$ duration than those with distal RBBB. These differences between proximal and distal RBBB could be caused by the severity and/or completeness of the conduction delay, as well as the area blocked (which was greater in proximal RBBB). 


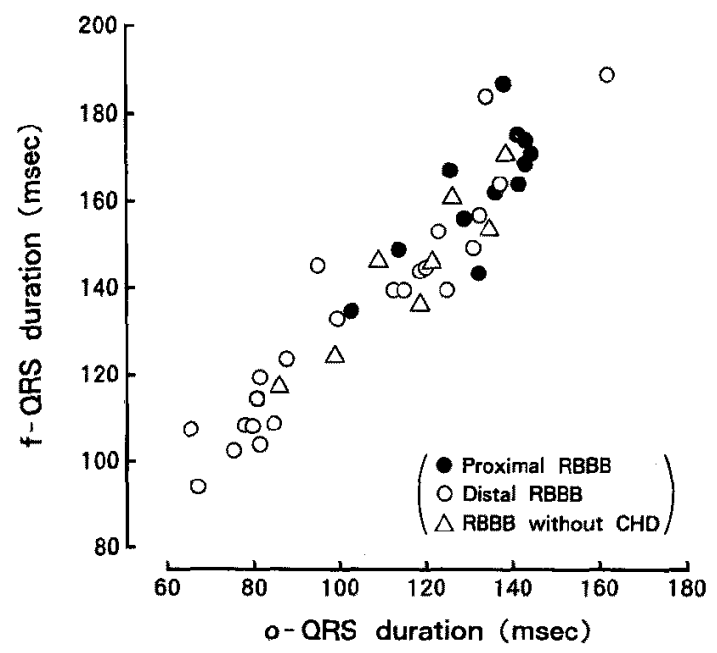

Fig. 5. The correlation between the filtered QRS duration and the original QRS duration. $\mathrm{GHD}=$ congenital heart disease; $\mathrm{f}-\mathrm{QRS}=$ filtered $\mathrm{QRS} ; \mathrm{o}-$ $\mathrm{QRS}=$ original $\mathrm{QRS} ; \mathrm{RBBB}=$ right bundle branch block.
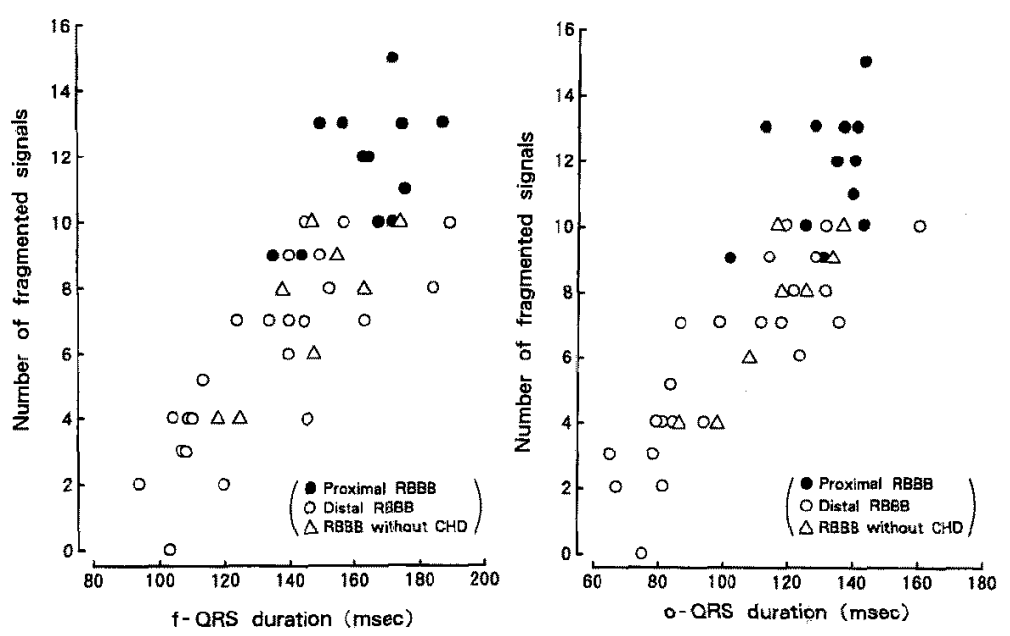

Fig. 6. The correlations between the filtered QRS duration and the original QRS duration, and the number of fragmented signals. Abbreviations are the same as those in Fig. 5.

Most patients with proximal RBBB generally have shown complete RBBB. ${ }^{2)}$ In fact, our study on SAECG also demonstrated that complete RBBB was more common than incomplete RBBB in patients with proximal RBBB. The $\mathrm{f}-\mathrm{QRS}$ duration was as prolonged as the $\mathrm{o}-\mathrm{QRS}$ duration (Fig. 5). Moreover, the number of FS correlated with the prolongation of the $0-Q R S$ duration $(r=0.84, p<0.01 ;$ Fig. 6). This finding enabled us to detect delayed and 
heterogeneous ventricular conduction in the patients with $\mathrm{RBBB}$ compared to those with normal ventricular conduction. When only the durations of the oQRS and the $f-Q R S$ were evaluated, there was considerable overlap between the patients with proximal and distal RBBB. This required us to examine other parameters (e.g., the number of FS and the $f-$ QRS pattern) to determine those which could be useful in distinguishing proximal from distal RBBB. The "whole" type $f-Q R S$ pattern may indicate the width of the heterogeneous conduction area associated with the block site. It is likely that a more proximal block results in a wider and more delayed conduction area.

Some patients had both RBBB and late potentials after surgical correction of congenital heart disease. ${ }^{15)}$ The presence of late potentials probably increases $f-Q R S$ duration and the number of FS. The criteria for proximal RBBB by the SAECG have to be altered in such a situation. Therefore, those patients with RBBB and late potentials were excluded from this study. Further studies are required to investigate the relationship between the block site of $\mathrm{RBBB}$ and late potentials in such patients by use of the SAECG.

In conclusion, SAECG can be used with good sensitivity and negative predictive value for the noninvasive determination of the block site in patients who present with RBBB following surgical correction.

\section{ReFERENCES}

1. Horowitz LN, Alexander JA, Edmunds LH Jr: Postoperative right bundle branch block; identification of three levels of block. Circulation 62: 319, 1980

2. Sung RJ, Tamer DM, Garcia OL, Castellanos AC, Myerburg RJ, Gelband H: Analysis of surgicallyinduced right bundle branch block pattern using intracardiac recording techniques. Circulation 54: 442, 1976

3. Steeg GN, Krongrad E, Davachi F, Bowman FO, Malm JR, Gersony WM: Postoperative left anterior hemiblock and right bundle branch block following repair of tetralogy of Fallot. Circulation 51: 1026, 1975

4. Krongrad E: Prognosis for patients with congenital heart disease and postoperative intraventricular conduction defects. Circulation 57: 867, 1978

5. Simson MB, Untereker WJ, Spielman SR, Horowitz LN, Marcus NH, Falcone RA, Harken AH, Josephson ME: Relation between late potentials on the body surface and directly recorded fragmented electrograms in patients with ventricular tachycardia. Am J Cardiol 51: 105, 1983

6. Taccardi B, DeAmbroggi L, Riva D: Chest maps of heart potentials in right bundle branch block. J Electrocardiol 2: 109, 1969

7. Liebman J, Rudy Y, Dias P, Thomas CW, Plonsey R: The spectrum of right bundle branch block as manifested in electrocardiographic body surface potential maps. J Electrocardiol 17: 329, 1984

8. Simson MB: Identification of patients with ventricular tachycardia after myocardial infarction from signals in the terminal QRS complex. Circulation 64: 235, 1981

9. Denes P, Santarelli P, Hauser RG, Uretz EF: Quantitative analysis of the high frequency component of the terminal portion of the body surface QRS in normal subjects and in patients with ventricular tachycardia. Círculation 67: 1129, 1983

10. El-Sherif N, Gomes J, Restivo M, Mehra R: Late potentials and arrhythmogenesis. PACE 8: 4t0, 1985 
11. Ozawa $Y$, Yakubo S, Tanigawa N, Nagasawa M, Kojima R, Jinno K, Hibiya K, Watanabe I, Saito T, Saito S, Hatano M: The clinical evaluation of the late potentials in patients with ventricular arrhythmias. Jpn Circ J 51: 230, 1987

12. Breithardt $G$, Becker R: Non-invasive detection of late potentials in man: A new marker for ventricular tachycardia. Eur Heart J 2: 1, 1981

13. Rozanski JJ, Mortara D, Myerburg RJ, Castellanos A: Body surface detection of delayed depolarizations in patients with recurrent ventricular tachycardia and left ventricular aneurysm. Circulation 63: 1172, 1981

14. Breithaedt G, Borggrefe M, Karbenn U, Abendroth RR, Yen HL, Seipel L: Prevalence of late potentials in patients with and without ventricular tachycardia: Correlation with angiographic findings. Am J Cardiol 49: 1932, 1982

15. Matsuoka S, Akita H, Taguchi Y, Kubo M, Kitagawa T, Miki O, Katoh I, Kuroda Y: Clinical significance of late potentials in patients after intracardiac operation for congenital heart disease. Jpn Circ J 56: 641, 1992

16. Buckingham TA, Thessen CC, Stevens LL, Redd RM, Kennedy HL: Effect of conduction defects on the signal-averaged electrocardiographic determination of late potentials. Am J Cardiol 61: 1265, 1988

17. Zimmermann M, Friedi B, Adamec R, Oberhansli I: Frequency of ventricular late potentials and fractionated right ventricular electrograms after operative repair of tetralogy of Fallot. Am J Cardiol 59: 448,1987

18. Stelling JA, Danford DA, Kugler JD, Windle JR, Cheatham JP, Gumbiner CH, Latson LA, Hofschire PJ: Late potentials and inducible ventricular tachycardia in surgically repaired congenital heart disease, Circulation 82: 1690, 1990

19. Fontaine JM, Rao R, Henkin R, Suneja R, Ursell SN, El-Sherif N: Study of the influence of left bundle branch block on the signal-averaged electrocardiogram: A qualitative and quantitative analysis. Am Heart J 121: 494, 1991 